Proc. Indian Acad. Sci. (Earth Planet. Sci.), Vol. 95, No. 3, November 1986, pp. 343-349. (C) Printed in India.

\title{
Analysis of gravimagnetic anomalies by horizontal gradients
}

\author{
G RAMADASS, S M VARAPRASADA RAO and A RAJA \\ MOHAMMED* \\ Centre of Exploration Geophysics, Osmania University, Hyderabad 500 007, India \\ ${ }^{*}$ Geohydrological Investigation Scheme, AFPRO, Coimbatore 641002 , India
}

MS received 3 August 1985; revised 15 January 1986

\begin{abstract}
A simple technique for the interpretation of gravimagnetic anomalies by a numerical differentiation is presented. The ratio of horizontal gradient to the observed field was used for the location of the origin and depth to the causative body. This technique was tested by using fundamental expressions due to sphere, horizontal cylinder and vertical fault models and field data over a spherical body. It has been found that the depth to the centre of the body can be determined accurately by this technique.
\end{abstract}

Keywords. Horizontal gradients; gravimagnetic interpretation; horizontal cylinder; vertical fault.

\section{Introduction}

Interpretation of gravity anomalies making use of gradients are being increasingly employed. Notable work in this field have been carried out by several workers (Hood 1965; Hood and McClure 1965; Stanley and Green 1976; Radhakrishna Murthy 1980; Acthuta Rao et al 1981; Gupta 1983).

In the present paper a method is proposed for interpreting some of the gravity and magnetic anomalies by considering only the horizontal gradients. The method is illustrated with a few theoretical and field examples pertaining to sphere, horizontal cylinder and vertical fault. The accuracy of the results obtained by this technique depends upon the accuracy of the initial gravimagnetic data.

\section{Basis of method}

The vertical component of gravity field $(\Delta g)$ and that of vertical magnetic field polarized in vertical direction $(\Delta Z)$ due to sphere (figure 1a), horizontal cylinder (figure 1b) and vertical fault (figure 1c) are given by Dobrin (1976). The gravity expression in a $\mathrm{X}-\mathrm{Z}$ plane in general can be defined as

$$
\Delta g(x, z)=K g(x, z)
$$

where

$$
g(x, z)=\left\{\begin{array}{lll}
z /\left(x^{2}+z^{2}\right)^{3 / 2} & K=4 \pi G \sigma R^{3} / 3 & \text { for a sphere } \\
Z /\left(x^{2}+z^{2}\right) & K=2 \pi G \sigma R^{2} & \text { for a horizontal (2) } \\
& & \text { cylinder } \\
{\left[\frac{1}{2} \pi-\tan ^{-1}(x / z)\right]} & K=2 \pi G \sigma t & \text { for a vertical fault }
\end{array}\right.
$$



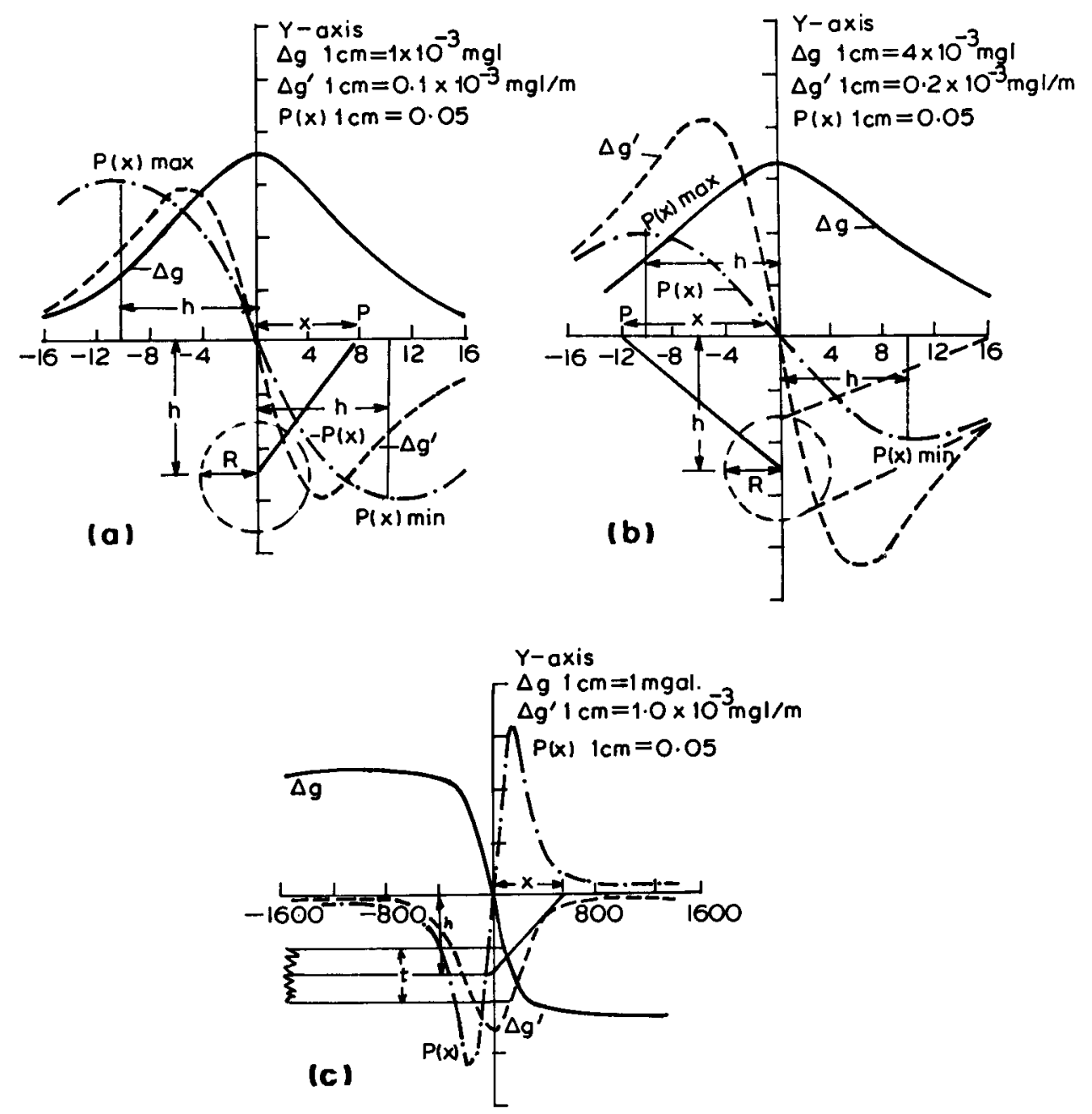

Figure 1. Theoretical curves of $\Delta g, \Delta g^{\prime}$ and $P(x)$ for (a) sphere (b) horizontal cylinder and (c) vertical fault gravity models.

Similarly the magnetic expression in a $\mathrm{X}-\mathrm{Z}$ plane can be written as

$$
\Delta Z(x, z)=K_{1} Z(x, z)
$$

where

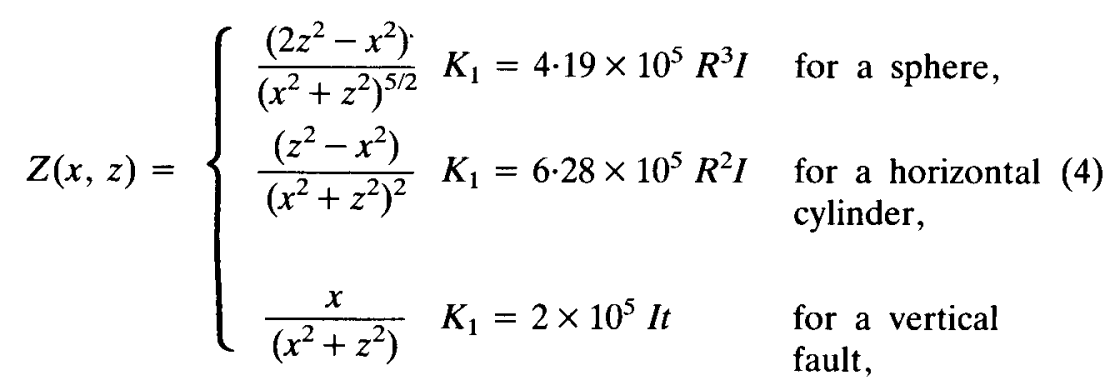


where $G$ denotes the universal gravity constant, $\sigma$ the density contrast, $R$ the radius, $l$ the magnetization, $Z$ the depth to the body, $t$ the thickness of the fault, $\Delta g(x)$ and $\Delta Z(x)$ are the vertical component of gravity and magnetic intensity in milligals and gammas respectively.

By differentiating (2) and (4) with respect to $x$, the respective horizontal gradients for gravity are

$$
\Delta g^{\prime}(x, z)=K^{\prime} g^{\prime}(x, z)
$$

where

$$
g^{\prime}(x, z)=\left\{\begin{array}{lll}
z x /\left(x^{2}+z^{2}\right)^{5 / 2} & K^{\prime}=-4 \pi G R^{3} \sigma & \text { for a sphere } \\
z x /\left(x^{2}+z^{2}\right)^{2} & K^{\prime}=-4 \pi G R^{2} \sigma & \text { for a horizontal } \\
& & \text { cylinder } \\
z /\left(x^{2}+z^{2}\right) & K^{\prime}=2 G t \sigma \pi & \text { for a vertical fault }
\end{array}\right.
$$

Similarly for a magnetic case

$$
\Delta Z^{\prime}(x, z)=K_{1}^{\prime} Z^{\prime}(x, z)
$$

where

$$
Z^{\prime}(x, z)= \begin{cases}\frac{3 x\left(x^{2}-4 z^{2}\right)}{\left(x^{2}+z^{2}\right)^{7 / 2}} K_{1}^{\prime}=4 \cdot 19 \times 10^{5} R^{3} I & \text { for a sphere, } \\
\frac{x\left(x^{2}-3 z^{2}\right)}{\left(x^{2}+z^{2}\right)^{2}} K_{1}^{\prime}=12.56 \times 10^{5} R^{2} I & \begin{array}{l}
\text { for a horizontal }(8) \\
\text { cylinder, }
\end{array} \\
\frac{\left(z^{2}-x^{2}\right)}{\left(x^{2}+z^{2}\right)^{2}} K_{1}^{\prime}=2 \times 10^{5} I t & \text { for a vertical } \\
& \text { fault, }\end{cases}
$$

In each case, dividing the first horizontal derivative of the field by its corresponding gravity and magnetic field, we obtain in the case of gravity

$$
P(x)=\Delta g^{\prime}(x, z) / \Delta g(x, z)
$$

where

$$
P(x)= \begin{cases}-3 x /\left(x^{2}+z^{2}\right) & \text { for a sphere } \\ -2 x /\left(x^{2}+z^{2}\right) & \text { for a horizontal cylinder } \\ z /\left(\pi / 2-\tan ^{-1}(x / z)\right)\left(x^{2}+z^{2}\right) & \text { for a vertical fault }\end{cases}
$$

In the case of magnetic,

$$
Q(x)=\Delta Z^{\prime}(x, z) / \Delta Z(x, z)
$$


where

$$
Q(x)= \begin{cases}\frac{3 x\left(x^{2}-4 z^{2}\right)}{\left(x^{2}+z^{2}\right)\left(2 z^{2}-x^{2}\right)} & \text { for a sphere, } \\ \frac{2 x\left(x^{2}-3 z^{2}\right)}{\left(x^{2}+z^{2}\right)\left(z^{2}-x^{2}\right)} & \text { for a horizontal cylinder } \\ \frac{\left(z^{2}-x^{2}\right)}{x\left(x^{2}+z^{2}\right)} & \text { for a vertical fault, }\end{cases}
$$

where $\Delta g^{\prime}(x, z)$ and $\Delta Z^{\prime}(x, z)$ are their respective derivatives with respect to $x P(x)$ is the ratio of $\left(\Delta g^{\prime} / \Delta g\right)$ and $Q(x)$ is the ratio of $\left(\Delta Z^{\prime} / \Delta Z\right)$.

Using (11) and (12) $z$ can be obtained for gravity as:

$$
Z= \begin{cases}\left(\frac{-3 x}{P(x)}-x^{2}\right)^{1 / 2} & \text { for a sphere, } \\ \left(\frac{-2 x}{P(x)}-x^{2}\right)^{1 / 2} & \text { for a horizontal cylinder } \\ \frac{2}{\pi P(x)} & \text { for vertical fault } \\ \text { when } x=0\end{cases}
$$

In the case of magnetic

$$
Z= \begin{cases} \pm x / 2 & \text { for sphere at } Q(x)=0 \\ \pm x /(3)^{1 / 2} & \text { for a horizontal cylinder } Q(x)=0 \\ \pm x & \text { for vertical fault } Q(x)=0\end{cases}
$$

\section{Theoretical examples}

The technique presented is illustrated with the construction of theoretical curves based on (2), (4), (6) and (8) fo. sphere, horizontal cylinder and vertical fault. The first horizontal derivatives of the gravimagnetic effects are shown in figures 1a, 1b and $1 \mathrm{c}$ and figures $2 \mathrm{a}, 2 \mathrm{~b}$ and $2 \mathrm{c}$ respectively, which also include the plots of $P(x)$ and $Q(x)$ values.

With the knowledge of the $P(x)$ and $Q(x)$ and using equations (13) and (14) $z$ can be evaluated for any value of $x$.

In addition to the above analysis the depth of sphere and horizontal cylinder can also be determined from $P(x)$ and $Q(x)$ values. The values of abscissa at which the function acquires an extrema may be found from the condition $\mathrm{d} P(x) / \mathrm{d} x$ and $\mathrm{d} Q(x) / \mathrm{d} x=0$.

The functions $P(x)$ and $Q(x)$ for sphere and horizontal cylinder attain the maximum when $x$ is negative and minimum when $x$ has positive values. The distance from the origin to the maxima or minima of the $P(x)$ and $Q(x)$ curves directly gives the depth to the centre of the body for sphere (figure 1a) and 

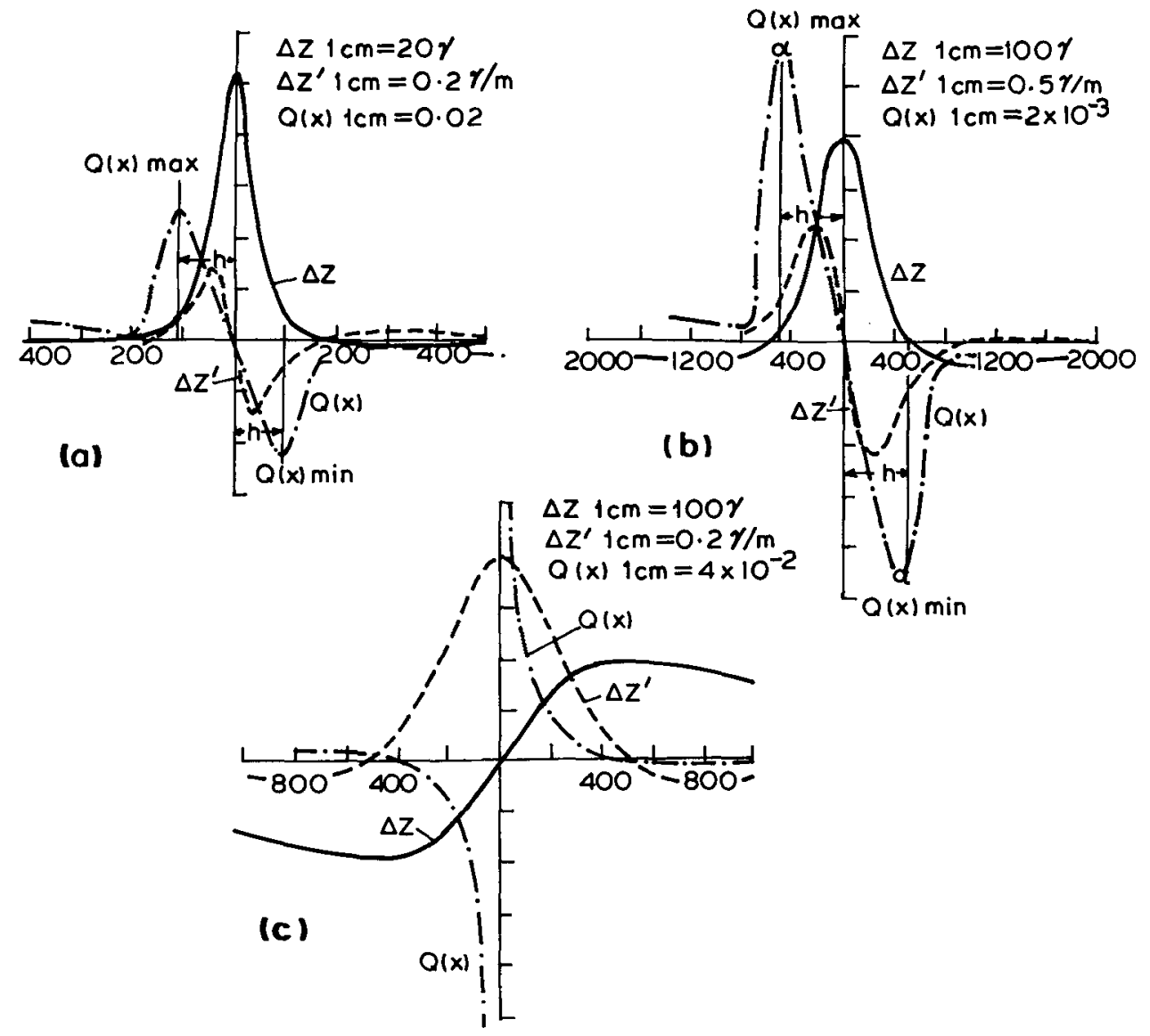

Figure 2. Theoretical curves of $\Delta Z, \Delta Z^{\prime}$ and $Q(x)$ for (a) sphere (b) horizontal cylinder and (c) vertical fault magnetic models.

horizontal cylinder (figure 1b) in the case of gravity and magnetic sphere (figure 2a) whereas in the case of magnetic horizontal cylinder (figure $2 b$ ), the distance from origin to maximum $(Q(x) \rightarrow \infty)$ or minimum $(Q(x) \rightarrow-\infty)$ gives the depth to the centre of the cylinder.

\section{Field examples}

The applicability of the technique is tested with field data pertaining to the gravity anomaly over saltdome shown in figure 3a (Nettleton 1976) and the magnetic anomaly over profile $C C^{\prime}$ on the vertical intensity anomaly map of the Bankhura area (Verma and Bandopadyay 1975) and are shown in figure 3b. In both cases, the structures are assumed to be sphere. and the interpretation is carried out. The interpreted results closely agree with those of Nettleton (1976) and Verma and Bandopadhyay (1975) as can be seen from table 1. 

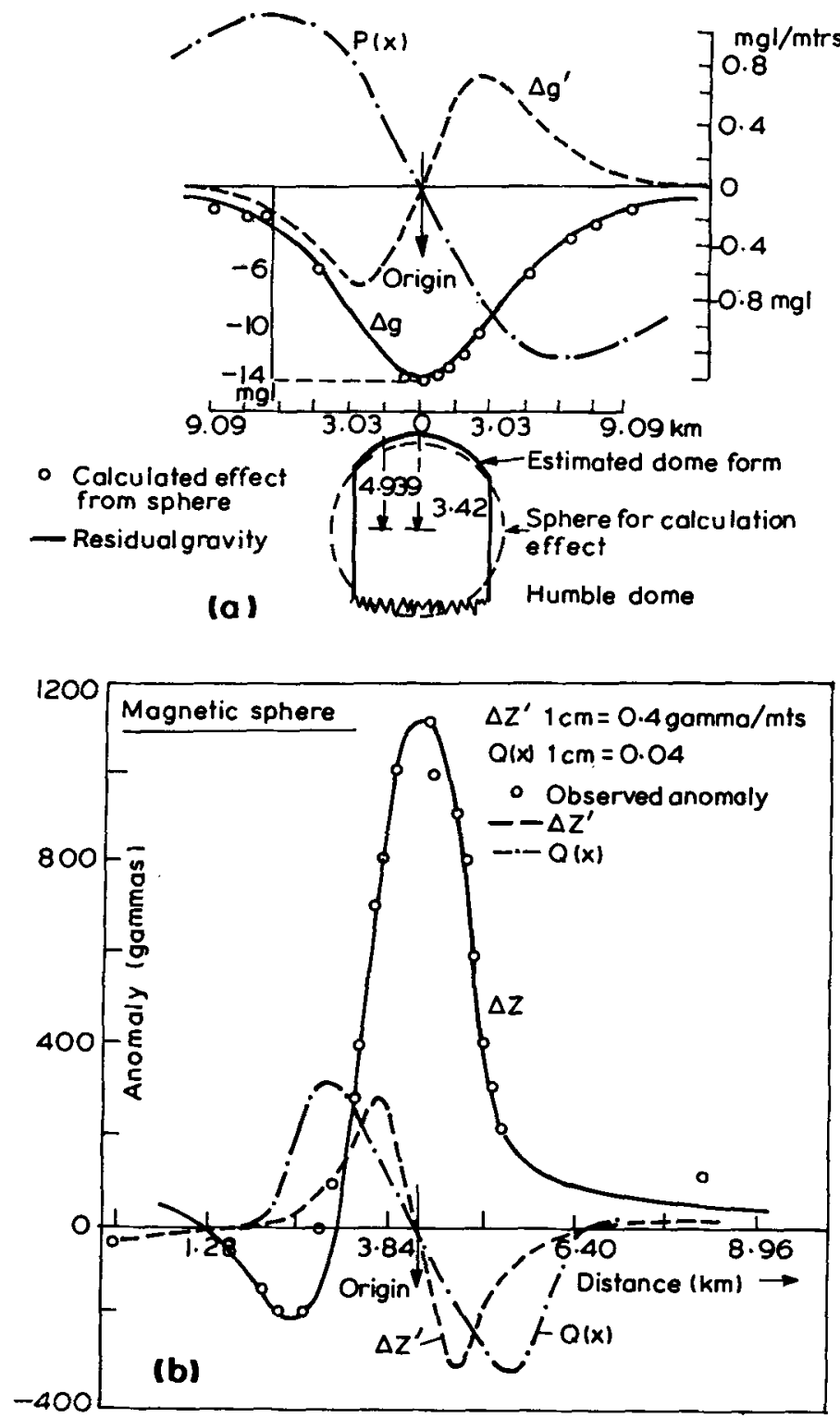

Figure 3. Illustration of horizontal gradients techniques over (a) gravity and (b) magnetic field examples.

\section{Discussion of the results}

It was verified numerically that (13) and (14) give the exact value of $z$ when using synthetic data. After adding $\pm 5 \%$ random error in the synthetic data (table 2 ), the depth obtained by the present method is within $\pm 5 \%$ error in the spherical model. 
Table 1. Comparative study of depths

\begin{tabular}{cccccc}
\hline & Gravity $(\mathrm{km})$ & \multicolumn{3}{c}{ Magnetics $(\mathrm{km})$} & Other \\
\cline { 2 - 6 } & $\begin{array}{c}\text { Calculated } \\
\text { values } \\
\text { (Present } \\
\text { method) }\end{array}$ & $\begin{array}{c}\text { Reported } \\
\text { values } \\
\text { (Nettleton } \\
1976)\end{array}$ & $\begin{array}{c}\text { Calculated } \\
\text { values } \\
\text { (Present } \\
\text { method) }\end{array}$ & $\begin{array}{c}\text { Reported } \\
\text { values } \\
\text { (Rao 75) }\end{array}$ & $\begin{array}{c}\text { (Mohan } \\
\text { et al } \\
1982)\end{array}$ \\
\hline$h$ & 4.94 & 4.94 & 1.31 & 1.31 & 1.30 \\
\hline$R$ & 3.42 & 3.42 & 1.09 & 1.00 & 1.00 \\
\hline
\end{tabular}

Table 2. Theoretical gravity (sphere) results

\begin{tabular}{cccr}
\hline $\begin{array}{c}\text { Model } \\
\text { depth } \\
\text { (in m) }\end{array}$ & $\begin{array}{c}\text { Using } \\
\text { synthetic } \\
\text { data } \\
\text { (in m) }\end{array}$ & $\begin{array}{c}\text { Using data } \\
\text { with random } \\
\text { errors } \pm 5 \% \\
\text { (in m) }\end{array}$ & $\begin{array}{c}\text { Percentage } \\
\text { of error }\end{array}$ \\
\hline 100 & 100 & 102 & 1.96 \\
200 & 200 & 198 & -1.01 \\
300 & 300 & 310 & 3.23 \\
400 & 400 & 397 & -0.76 \\
500 & 500 & 503 & 0.63 \\
600 & 600 & 609 & 1.64 \\
800 & 800 & 801 & $0 \cdot 12$ \\
1000 & 1000 & 1050 & 4.76 \\
\hline
\end{tabular}

From the above analysis it is evident that the characteristics of gradients $P(x)$ and $Q(x)$ curves in gravimagnetic analysis can provide fairly accurate estimates of the depths and other parameters of the buried objects.

\section{References}

Acthuta Rao D, Rambabu H V and Sankar Narayan P V 1981 Geophysics 461572

Dobrin M B 1976 Introduction to geophysical prospecting (New York: McGraw-Hill) pp 467

Gupta O P 1983 Geophysics 48357

Hood P 1965 Geophysics 30891

Hood P and Mcclure P J 1965 Geophysics 30403

Mohan N L, Prasad N B R, Seshagiri Rao S V and Bhimasankaram V L S 1982 Bull. Aust. Soc. Explor. 1335

Nettleton L L 1976 Gravity and magnetic in oil prospecting (New York: McGraw-Hill) pp 205

Radhakrishna Murthy I V, Visweswara Rao C and Gopalakrishna G 1980 Proc. Indian Acad. Sci.

(Earth Planet. Sci.) 8931

Stanely J M and Green R 1976 Geophysics 411370

Verma R K and Bandopadhyay R R 1975 Indian J. Earth Sci. 2117 